\title{
Validity of Brief Pain Inventory Questionnaire in Describing Trigeminal Neuralgia and Temporomandibular Joint Disorder Patients
}

\section{K Caroline Sunitha ${ }^{1 *}$ and Arvind Muthukrishnan ${ }^{2}$}

${ }^{1}$ Associate Professor, Department of Oral Medicine and Radiology, Esic Dental

College, Kalaburagi, Karnataka, India

${ }^{2}$ Professor, Department of Oral Medicine and Radiology, Saveetha Dental College

and Hospital, Saveetha Institute of Medical and Technical Sciences, India

*Corresponding Author: K Caroline Sunitha, Associate Professor, Department of

Oral Medicine and Radiology, Esic Dental College, Kalaburagi, Karnataka, India
Received: October 25, 2021

Published: December 02, 2021

(C) All rights are reserved by $\mathbf{K}$ Caroline

Sunitha and Arvind Muthukrishnan.

\begin{abstract}
Background and Objectives: Multidimensional pain assessment plays an important role in evaluating diagnosis and treatment. The aim and objectives of the present study is to identify the descriptors for trigeminal neuralgia and temporomandibular joint disorder patients using the brief pain inventory questionnaire and to evaluate its validity and assess the discriminative capacity of the questionnaire in the same patients respectively.

Materials and Methods: Total sample of 144 patients was divided into two groups' i.e., trigeminal neuralgia (72) and temporomandibular joint disorder (72). After obtaining ethical clearance and consent from pain patients with trigeminal neuralgia or temporomandibular joint disorder, using the Standard English version of brief pain inventory questionnaire, the patients were asked to select a descriptor which best describes their pain intensity and the pain severity and interference was graded. The attending oral physician interviewed and filled in the questionnaire based on the patient's responses (clinician administered questionnaire). After completion of the questionnaire, the scores were analyzed and necessary treatments were given to all the patients.

Results: Patients in trigeminal neuralgia group chose "sharp, stabbing, shooting, burning, numb and unbearable" and in temporomandibular joint disorder group chose "aching, nagging" to describe their pain. Chi-square test was done to compare the proportions between these two pain groups $p$ - value was significant $(p<0.001)$. Correlations between pain intensity and pain interference scores in both the study groups showed a positive value for Pearson's coefficient $(r)=0.614$ and high statistical significance ( $p<0.001)$. Factor analysis done with rotated component matrix and Varimax with Kaiser Normalization method to identify factor loadings for pain intensity and pain interference scores revealed two factors and the p-value was significant. Receiver operating curve analysis was done to find a best cut off value for activity score to categorize between trigeminal neuralgia and temporomandibular joint disorder and the area under the curve was 0.624 with a sensitivity, specificity, negative predictive value, positive predictive value, overall accuracy to be $45.8 \%, 76.4 \%, 58.5 \%, 66.0 \%, 61.1 \%$ respectively. For sleep score, the area under curve was 0.651 and the sensitivity, specificity, negative predictive value, positive predictive value and overall accuracy was $68.1 \%, 58.3 \%, 64.6 \%, 62 \%$, and $63.2 \%$ respectively.

Conclusion: Though area under curve, sensitivity and specificity of BPI are not excellent, it has higher value than a random classifier. In conclusion, brief pain inventory use as a diagnostic tool alone can be improved by developing new questions and precision tests in further clinical studies.
\end{abstract}

Keywords: Pain, Trigeminal Neuralgia; Temporomandibular Joint Disorder; Brief Pain Inventory; Validity 


\section{Abbreviations}

TN: Trigeminal Neuralgia; TMD: Temporomandibular Joint Disorder; QoL: Quality of Life; HrQoL: Health Related Quality of Life; BPI: Brief Pain Inventory; REM: Relations with Others, Enjoyment of Life, Mood; WAW: Walking, General Activity and Work; MPQ: McGill Pain Questionnaire; IHS: International Headache Society; RDC: Research Diagnostic Criteria; KMO Bartlett's Test: Kaiser-MeyerOlkin; ROC: Receiver Operating Curve; AUC: Area Under Curve; Sn: Sensitivity; Sp: Specificity; PPV: Positive Predictive Value; NPV: Negative Predictive Value; IASP: International Association for the Study of Pain; WHO: World Health Organization.

\section{Introduction}

Pain is one of the most common symptoms in orofacial region and is mostly due to odontogenic and non-odontogenic causes (neurological, vascular and musculoskeletal pathologies) [1]. Among such orofacial pains are trigeminal neuralgia (TN) and pains due to temporomandibular joint disorders (TMD). Assessment of pain and its associated characteristics helps in obtaining detailed information about the patient and monitoring their progress over time post intervention. It also helps in comparing one patient with another from a similar disease population. The diagnosis of a majority of the orofacial pains is based on a careful history and clinical examination. Pain involves cognitive, motivational, effective, behavioral and physical components and is multi-dimensional in that the sensory dimension of pain includes pain intensity or pain severity and the reactive dimension of pain includes its interference with daily function [2,3]. Hence, a good pain assessment should include quality and quantity of pain as well as its interference on the quality of life (emotional and psychological impact). The diagnosis of a majority of the orofacial pains is based on a careful history and clinical examination. Often, the usual clinical exchange about pain between the doctor and the patient is so casual or unstructured that poor pain assessment is assured [4]. Questionnaire is one of the key tools in research consisting of a series of questions and other prompts for the purpose of gathering information from respondents. Unidimensional pain questionnaires measure only the sensory dimension i.e. pain intensity in the form of scales whereas the multidimensional pain questionnaires measure both the sensory as well as reactive component (pain interference). Since pain is multidimensional, assessing the pain through multidimensional questionnaires is of great help to the clinician in evaluation of both diagnosis and prognosis [5].

One such multi-dimensional pain questionnaires is the Brief pain inventory (BPI) questionnaire which was first developed by the pain research group of the WHO collaborating Centre for symptom evaluation in cancer care to measure the cancer pain in 1970s [6]. It contains questions related to pain severity (as pain least, average, worst and right now) and pain interference as (an affective sub dimension REM: relations with others, enjoyment of life, and mood and an activity sub dimension WAW: walking, general activity, and work). The BPI uses 0-10 numerical rating scales (due to its simplicity and lack of ambiguity) to assess the interference of pain with mood, walking, general activity, work, relations with others, sleep and enjoyment of life. The mean of these scores can be used as a pain interference score which is highly correlated with an interference factor derived from a common factor analysis solution. As ratings on pain worst increase, additional pain interference items are rated as impaired. BPI also contains diagrams where the patients are asked to mark their pain location(s) on front/back body diagrams and to describe their perception of the cause of pain, the types of pain treatment they were receiving, and the amount of relief provided by their treatment. A potential aid to diagnosis that merits investigation is the different verbal descriptors used by patients to describe their pain. In BPI, to describe the quality of pain, the patients are asked to choose words among a list of fifteen verbal descriptors (derived from the McGill Pain Questionnaire).

\section{Materials and Methods}

The study population consisted of a total of 144 patients and they were divided into two groups (Group-1TN=72, Group-2 $\mathrm{TMD}=72$ ). The sample size was calculated by $80 \%$ power of the study with Alpha Error (\%) = 5 .

\section{Inclusion and exclusion criteria}

Symptomatic patients (both men and women) aged 18 years and above who have been diagnosed with trigeminal neuralgia (IHS criteria) and temporomandibular joint disorder (RDC criteria) have been included in this study $[7,8]$. Patients with a history of surgical management for TN and TMD and other causes of orofacial pain, pregnant patients, medically compromised patients (with 
definitive systemic illness other than TN and TMD) have been excluded for this study.

\section{Methodology}

After obtaining approval from the institutional scientific and ethical committee (SRB/SDMDS120MR1,IHEC/SDMDS120MR1) the study was started. After obtaining consent, the patients attending the department of oral medicine and radiology with a complaint of pain were taken in this study once they have been diagnosed with TN or TMD based on history, examinations and imaging techniques whenever indicated. The Standard English version of BPI questionnaire was used in this study. The patients were asked to grade pain severity and the disability caused by pain on their daily functional activities. Also, they were asked to select a descriptor which describes their pain intensity. The attending oral physician interviewed and filled in the questionnaire based on the patient's responses (clinician administered questionnaire). After completion of the questionnaire, necessary treatments were given to all the patients.

\section{Analysis of the pain scores}

The total scores on the subscale of pain interference with functions are calculated by adding the scores for each item on pain interference. The four severity and the seven interference items can also each be summed to form composite scores [6].

\section{Results and Discussion}

Results

A total of 144 were present in the study population. The data was entered into an excel sheet and analyzed by SPSS version 18.

\section{Age and gender groups}

Table 1 shows the distribution subjects in different age groups among the study population. TN was more prevalent in the age group between $41-50$ years (54.2\%) and above 60 years (40.3\%) On the other hand, TMD was more prevalent among the age group of 21-40 years (63.9\%).The data in table 2 shows distribution of males and females in the study population. $49.3 \%$ (71) were males and $50.7 \%$ (73) were females among the total participants in the study. In the TMD group, there were 29 males and 43 females. In the TN group, there were 42 males and 30 females.

\begin{tabular}{|c|c|c|c|}
\hline $\begin{array}{c}\text { Age of study } \\
\text { subjects }\end{array}$ & TMD & TN & Total \\
\hline$<20$ years & 8 & 0 & 8 \\
& $11.1 \%$ & $0 \%$ & $5.6 \%$ \\
\hline $21-40$ years & 46 & 4 & 50 \\
& $63.9 \%$ & $5.6 \%$ & $34.7 \%$ \\
\hline $41-50$ years & 15 & 39 & 54 \\
& $20.8 \%$ & $54.2 \%$ & $37.5 \%$ \\
\hline$>60$ years & 3 & 29 & 32 \\
& $4.2 \%$ & $40.3 \%$ & $22.2 \%$ \\
\hline Total & 72 & 72 & 144 \\
& $100.0 \%$ & $100.0 \%$ & $100.0 \%$ \\
\hline
\end{tabular}

Table 1: Distribution of age groups in the study population.

\begin{tabular}{|c|c|c|c|}
\hline $\begin{array}{c}\text { Gender of the } \\
\text { study subjects }\end{array}$ & TMD & TN & Total \\
\hline Males & 29 & 42 & 71 \\
\hline Females & 43 & 30 & 73 \\
& $59.7 \%$ & $41.7 \%$ & $50.7 \%$ \\
\hline Total & 72 & 72 & 144 \\
& $100.0 \%$ & $100.0 \%$ & $100.0 \%$ \\
\hline
\end{tabular}

Table 2: Distribution of males and females in the study population.

\section{Verbal descriptors}

The data in table 3 and figure 1 shows prevalence of verbal descriptors in TN and TMD groups. In our study, patients with TN chose mostly "sharp, stabbing, shooting, burning, numb and unbearable" to describe their pain. Statistical analysis revealed high significance for these words in describing pain of TN ( $p<0.001)$. Typical verbal descriptors among TMD patients were "aching, nagging" and they were statistically highly significant $(P<0.001)$ for TMD patients. Chi-square test was done to compare the proportions between these two pain groups and it revealed statistical significance of $(\mathrm{p}<0.001)$. 


\begin{tabular}{|c|c|c|c|c|c|c|c|c|}
\hline \multirow[t]{3}{*}{ Descriptor } & & \multicolumn{6}{|c|}{ Pain Group } & \multirow[t]{3}{*}{ P-Value } \\
\hline & \multicolumn{2}{|c|}{ TMD } & \multicolumn{2}{|c|}{ TN } & \multicolumn{2}{|c|}{ Total } & & \\
\hline & $\mathbf{N}$ & $\%$ & $\mathbf{N}$ & $\%$ & $\mathbf{N}$ & $\%$ & & \\
\hline \multirow[t]{3}{*}{ Aching } & Yes & 71 & 98.6 & 13 & 18.1 & 84 & 58.3 & \multirow[t]{3}{*}{$<0.001$} \\
\hline & No & 1 & 1.4 & 59 & 81.9 & 60 & 41.7 & \\
\hline & Total & 72 & 100.0 & 72 & 100.0 & 144 & 100.0 & \\
\hline \multirow[t]{3}{*}{ Throbbing } & Yes & 67 & 93.1 & 2 & 2.8 & 69 & 47.9 & \multirow[t]{3}{*}{$<0.001$} \\
\hline & No & 5 & 6.9 & 70 & 97.2 & 75 & 52.1 & \\
\hline & Total & 72 & 100.0 & 72 & 100.0 & 144 & 100.0 & \\
\hline \multirow[t]{3}{*}{ Shooting } & Yes & 10 & 13.9 & 58 & 80.6 & 68 & 47.2 & \multirow[t]{3}{*}{$<0.001$} \\
\hline & No & 62 & 86.1 & 14 & 19.4 & 76 & 52.8 & \\
\hline & Total & 72 & 100.0 & 72 & 100.0 & 144 & 100.0 & \\
\hline \multirow[t]{3}{*}{ Stabbing } & Yes & 17 & 23.6 & 72 & 100.0 & 89 & 61.8 & \multirow[t]{3}{*}{$<0.001$} \\
\hline & No & 55 & 76.4 & 0 & .0 & 55 & 38.2 & \\
\hline & Total & 72 & 100.0 & 72 & 100.0 & 144 & 100.0 & \\
\hline \multirow[t]{3}{*}{ Gnawing } & Yes & 36 & 50.0 & 11 & 15.3 & 47 & 32.6 & \multirow[t]{3}{*}{$<0.001$} \\
\hline & No & 36 & 50.0 & 61 & 84.7 & 97 & 67.4 & \\
\hline & Total & 72 & 100.0 & 72 & 100.0 & 144 & 100.0 & \\
\hline \multirow[t]{3}{*}{ Sharp } & Yes & 9 & 12.5 & 72 & 100.0 & 81 & 56.3 & \multirow[t]{3}{*}{$<0.001$} \\
\hline & No & 63 & 87.5 & 0 & .0 & 63 & 43.8 & \\
\hline & Total & 72 & 100.0 & 72 & 100.0 & 144 & 100.0 & \\
\hline \multirow[t]{3}{*}{ Tender } & Yes & 53 & 73.6 & 56 & 77.8 & 109 & 75.7 & \multirow[t]{3}{*}{0.560} \\
\hline & No & 19 & 26.4 & 16 & 22.2 & 35 & 24.3 & \\
\hline & Total & 72 & 100.0 & 72 & 100.0 & 144 & 100.0 & \\
\hline \multirow[t]{3}{*}{ Burning } & Yes & 0 & .0 & 49 & 68.1 & 49 & 34.0 & \multirow[t]{3}{*}{$<0.001$} \\
\hline & No & 72 & 100.0 & 23 & 31.9 & 95 & 66.0 & \\
\hline & Total & 72 & 100.0 & 72 & 100.0 & 144 & 100.0 & \\
\hline \multirow[t]{3}{*}{ Exhausting } & Yes & 2 & 2.8 & 0 & .0 & 2 & 1.4 & \multirow[t]{3}{*}{0.497} \\
\hline & No & 70 & 97.2 & 72 & 100.0 & 142 & 98.6 & \\
\hline & Total & 72 & 100.0 & 72 & 100.0 & 144 & 100.0 & \\
\hline
\end{tabular}

Table 3: Pain descriptors scores in TN and TMD Groups.

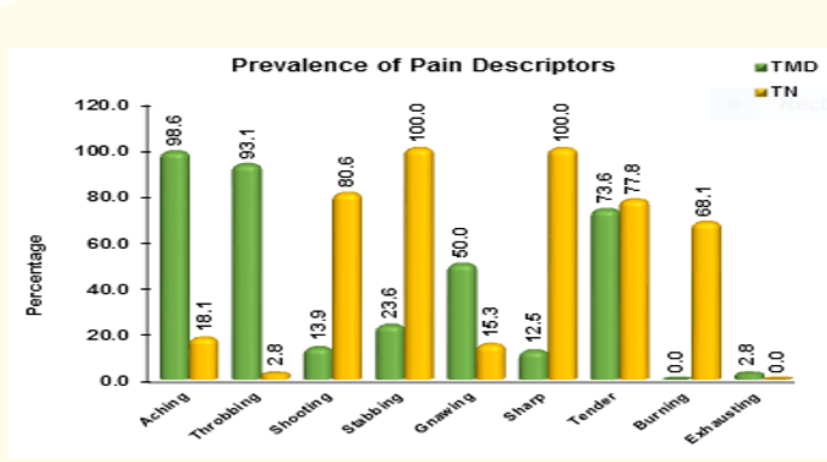

Figure 1: Pain descriptors in TN and TMD groups.
Mean pain intensity scores

The data in table 4 and figure 2 shows the mean pain intensity scores in the study. The mean values of pain intensity scores revealed that the mean worst pain in TMD group is 7.82 with a standard deviation of 1.117 where as in TN group it is 8.15 with a standard deviation of 1.016 . The independent sample t-test result shows that the two mean values are not significant $(p=0.063)$. The mean least pain in TMD group is 5.15 with a standard deviation of 1.933 where as in TN group it is 4.76 with a standard deviation of 1.682. The independent sample t-test result shows that the two mean values are not significant $(p=0.200)$. The mean average pain 
in TMD group is 6.08 with a standard deviation of 1.253 where as in TN group it is 6.40 with a standard deviation of 1.329. The independent sample t-test result shows that the two mean values are not significant $(\mathrm{p}=0.140)$. The mean pain now in TMD group is 6.94 with a standard deviation of 1.775 where as in TN group it is 6.76 with a standard deviation of 2.388 . The independent sample $\mathrm{t}$-test result shows that the two mean values are not significant $(\mathrm{p}$ $=0.607$ ).

\begin{tabular}{|c|c|c|c|c|c|c|}
\hline & $\begin{array}{c}\text { Pain } \\
\text { Group }\end{array}$ & N & Mean & $\begin{array}{c}\text { Standard } \\
\text { deviation }\end{array}$ & $\begin{array}{c}\text { t- } \\
\text { Value }\end{array}$ & $\begin{array}{c}\text { p- } \\
\text { value }\end{array}$ \\
\hline \multirow{2}{*}{$\begin{array}{c}\text { Worst } \\
\text { Pain }\end{array}$} & TMD & 72 & 7.82 & 1.117 & 1.873 & 0.063 \\
\cline { 2 - 5 } & TN & 72 & 8.15 & 1.016 & & \\
\hline \multirow{2}{*}{$\begin{array}{c}\text { Least } \\
\text { Pain }\end{array}$} & TMD & 72 & 5.15 & 1.933 & \multirow{2}{*}{1.288} & 0.200 \\
\cline { 2 - 5 } Average & 72 & 4.76 & 1.682 & & \\
\cline { 1 - 5 } Pain & TMD & 72 & 6.08 & 1.253 & \multirow{2}{*}{1.484} & 0.140 \\
\hline \multirow{2}{*}{$\begin{array}{c}\text { Pain } \\
\text { now }\end{array}$} & TMD & 72 & 6.40 & 1.329 & & \\
\cline { 2 - 5 } & TN & 72 & 6.76 & 2.388 & & \\
\hline
\end{tabular}

Table 4: Mean pain intensity scores.

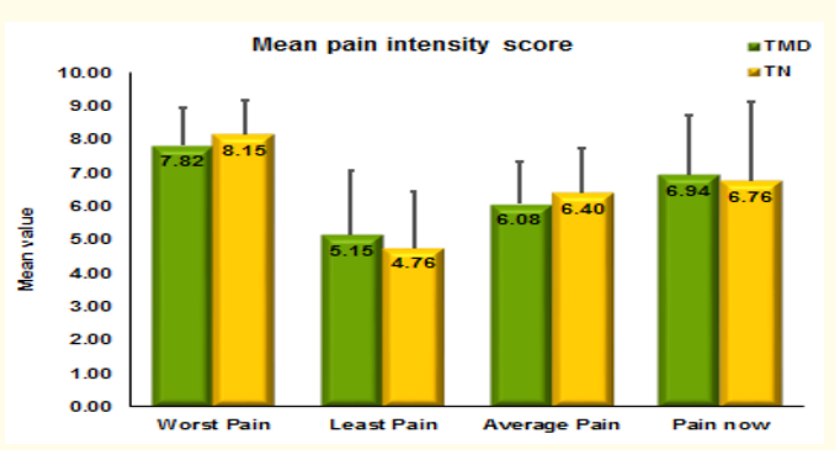

Figure 2: Mean pain intensity scores.

Mean pain interference scores

The data in table 5 and figure 3 shows the mean pain interference scores in the study. The mean values of pain interference scores in study subjects revealed statistical significance in both activity ( $p=0.035)$ and sleep $(p=0.693)$. The mean value of activity in TMD group is 6.65 with a standard deviation of 1.634 where as in TN group it is 7.15 with a standard deviation of 1.659. The independent sample $t$ - test result shows that the two mean values are statistically significant $(\mathrm{p}=0.035)$. The mean value of sleep in TMD group is 4.86 with a standard deviation of 1.849 where as in TN group it is 3.90 with a standard deviation of 1.929 . The independent sample t- test result shows that the two mean values are statistically significant $(\mathrm{p}=0.003)$.

\begin{tabular}{|c|c|c|c|c|c|c|}
\hline & $\begin{array}{c}\text { Pain } \\
\text { Group }\end{array}$ & $\mathbf{N}$ & Mean & $\begin{array}{l}\text { Std. } \\
\text { Dev }\end{array}$ & $\begin{array}{c}\text { t- } \\
\text { Value }\end{array}$ & $\begin{array}{c}\text { P- } \\
\text { Value }\end{array}$ \\
\hline \multirow[t]{2}{*}{ Activity } & TMD & 72 & 6.57 & 1.634 & \multirow[t]{2}{*}{2.126} & \multirow[t]{2}{*}{0.035} \\
\hline & $\mathrm{TN}$ & 72 & 7.15 & 1.659 & & \\
\hline \multirow[t]{2}{*}{ Mood } & TMD & 72 & 5.54 & 1.601 & \multirow[t]{2}{*}{0.235} & \multirow[t]{2}{*}{0.815} \\
\hline & $\mathrm{TN}$ & 72 & 5.61 & 1.932 & & \\
\hline \multirow[t]{2}{*}{ Walking } & TMD & 72 & 5.04 & 1.732 & \multirow[t]{2}{*}{0.142} & \multirow[t]{2}{*}{0.887} \\
\hline & $\mathrm{TN}$ & 72 & 5.08 & 1.790 & & \\
\hline \multirow[t]{2}{*}{ Work } & TMD & 72 & 5.76 & 1.873 & \multirow[t]{2}{*}{0.303} & \multirow[t]{2}{*}{0.762} \\
\hline & $\mathrm{TN}$ & 72 & 5.67 & 1.979 & & \\
\hline \multirow[t]{2}{*}{ Relationship } & TMD & 72 & 5.28 & 1.576 & \multirow[t]{2}{*}{0.396} & \multirow[t]{2}{*}{0.693} \\
\hline & $\mathrm{TN}$ & 72 & 5.17 & 1.784 & & \\
\hline \multirow[t]{2}{*}{ Sleep } & TMD & 72 & 4.86 & 1.849 & \multirow[t]{2}{*}{3.043} & \multirow[t]{2}{*}{0.003} \\
\hline & $\mathrm{TN}$ & 72 & 3.90 & 1.929 & & \\
\hline \multirow[t]{2}{*}{ Enjoyment } & TMD & 72 & 5.75 & 1.726 & \multirow[t]{2}{*}{0.001} & \multirow[t]{2}{*}{0.999} \\
\hline & $\mathrm{TN}$ & 72 & 5.75 & 1.867 & & \\
\hline
\end{tabular}

Table 5: Mean pain interference scores.

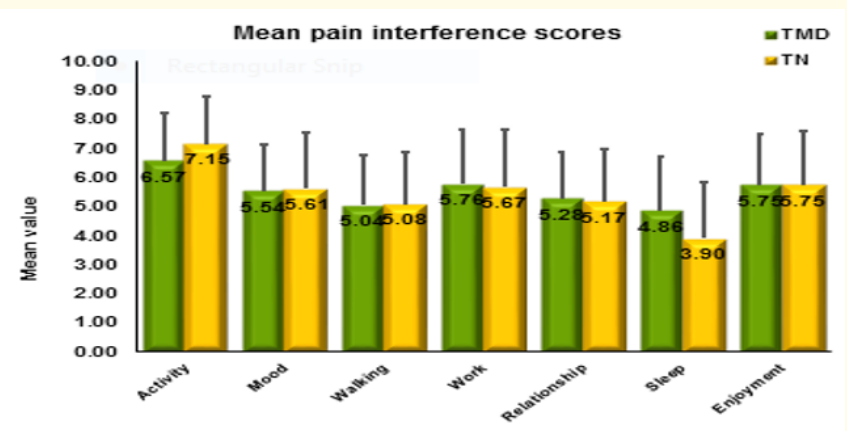

Figure 3: Mean pain interference scores.

Correlation between pain intensity and pain interference in both groups and in individual groups

The data in table 6 and figure 4 shows the correlation between pain intensity and pain interference in both groups in the study. 
Correlations between pain intensity and pain interference scores in both the study groups showed a positive value for Pearson's coefficient $(r)=0.614$ and high statistical significance $(p<0.001)$. The data in table 7 and figures 5 and 6 show the correlation between pain intensity and pain interference in each individual group in the study. Individually the correlation coefficients between pain intensity and pain interference showed $r=0.558$ in TMD group (Figure 5) and $r=0.676$ in TN group (Figure 6), both revealing high statistical significance $(\mathrm{p}<0.001)$.

\begin{tabular}{|c|c|c|}
\hline \multicolumn{2}{|c|}{} & Pain interference score (Total) \\
\hline $\begin{array}{c}\text { Pain intensity } \\
\text { score }\end{array}$ & $\begin{array}{c}\text { Pearson } \\
\text { Correlation }\end{array}$ & 0.614 \\
\cline { 2 - 3 } & P-Value & $<0.001$ \\
\cline { 2 - 3 } & $\mathrm{N}$ & 144 \\
\hline
\end{tabular}

Table 6: Correlation between pain intensity and pain interference in both groups.

\begin{tabular}{|c|c|c|c|}
\hline \multicolumn{3}{|c|}{ Pain Group } & \multirow{2}{*}{$\begin{array}{c}\text { Pain } \\
\text { interference } \\
\text { score (Total) } \\
0.558\end{array}$} \\
\hline \multirow[t]{3}{*}{ TMD } & \multirow{3}{*}{$\begin{array}{c}\text { Pain intensity } \\
\text { score }\end{array}$} & Pearson Correlation & \\
\hline & & P-Value & $<0.001$ \\
\hline & & $\mathrm{N}$ & 72 \\
\hline \multirow[t]{3}{*}{$\mathrm{TN}$} & \multirow{3}{*}{$\begin{array}{c}\text { Pain intensity } \\
\text { score }\end{array}$} & Pearson Correlation & 0.676 \\
\hline & & P-Value & $<0.001$ \\
\hline & & $\mathrm{N}$ & 72 \\
\hline
\end{tabular}

Table 7: Correlation between pain intensity and pain interference in individual groups.

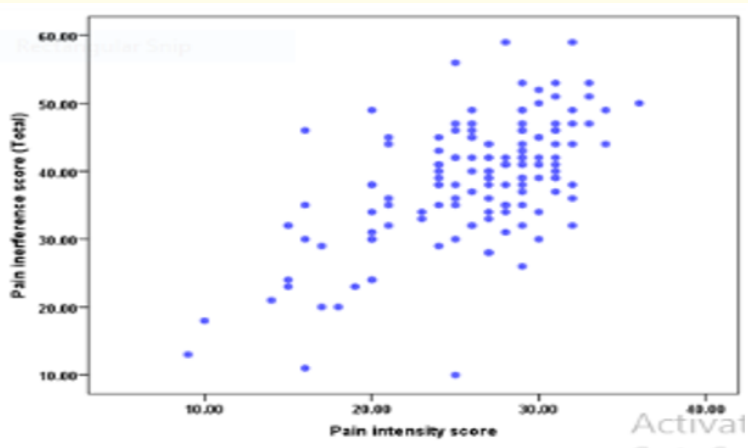

Figure 4: Correlations between pain intensity and pain interference scores in both groups.

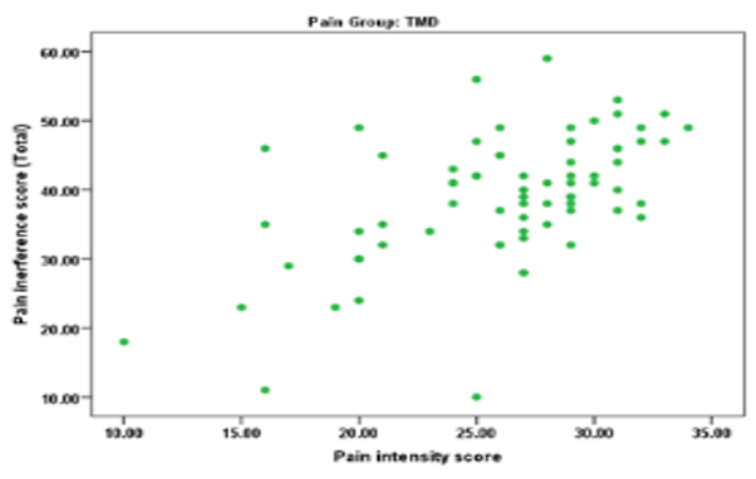

Figure 5: Correlation between pain intensity score and pain interference score in each group (TMD).

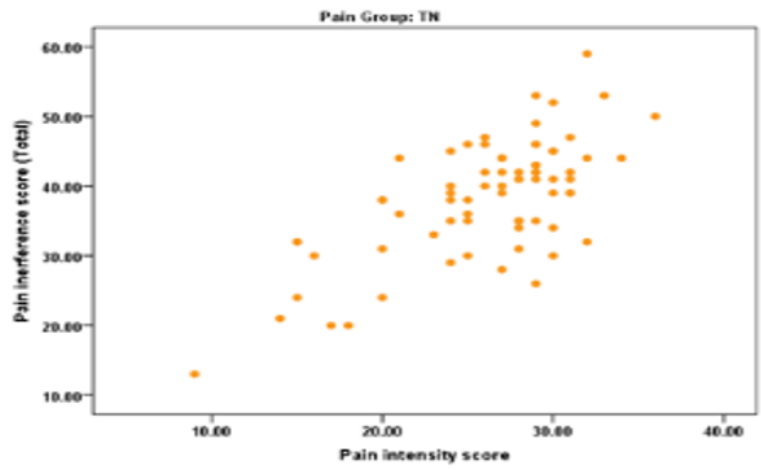

Figure 6: Correlation between pain intensity score and pain interference score in group (TN).

Factor analysis

Table 8 shows the factor analysis for pain intensity and pain interference in both TN and TMD groups. To identify the factor loadings for pain intensity and pain interference scores factor analysis was performed. Kaiser-Meyer-Olkin (KMO) Bartlett's test was done to test the model adequacy and its results showed that Kaiser-Meyer-Olkin(KMO) Measure of Sampling Adequacy is 0.857 with a $p$ value $<0.001$, indicating that the data is suitable for doing a factor analysis. The factor analysis was done with rotated component matrix and Varimax with Kaiser Normalization method. Usually, if the factor loading is more than 0.500 then factor grouping is considered. The results of the factor analysis identified two factors, one factor involved with all pain intensity variables and activity of pain interference and the other factor involved with all pain interference variables except activity. Factor analysis done for pain inten- 
sity and interference scores in TMD group showed KMO Bartlett's Measure of Sampling Adequacy to be 0.857 with a p value of $<0.001$ where as in TN group showed 0.807 with a p value of $<0.0001$. The data in table 9 shows the factor analysis values for pain intensity and pain interference in each individual group. When factor analysis for pain intensity and pain interference was done in each group, the same KMO Bartlett's test was done to test the model adequacy and the test results show that KMO Measure of Sampling Adequacy is 0.844 with a p-value $<0.001$ in TMD group (Table 9), which indicates that the data is suitable for doing a factor analysis. The factor analysis was done with rotated component matrix and Varimax with Kaiser Normalization method. The factor analysis result identifies two factors, one factor with all pain intensity variables and the other factor involving with all pain interference variables (Table 9). KMO Bartlett's test was done to test the model adequacy and the results of this test showed test that Kaiser-Meyer-Olkin Measure of Sampling Adequacy is 0.807 with a p-value $<0.001 \mathrm{in} \mathrm{TN}$ group, indicating that the data is suitable for doing a factor analysis. The factor analysis was done with rotated component matrix and Varimax with Kaiser Normalization method. The factor analysis results identified two factors, one factor with all pain intensity variables and the other factor evolves with all pain interference variables except walking (Table 9).

\begin{tabular}{|c|c|c|c|}
\hline \multicolumn{4}{|c|}{ KMO and Bartlett's Test } \\
\hline Kaiser-Meyer-Olkin Measure of Sampling Adequacy. & 0.857 \\
\hline Bartlett's Test of Sphericity & Approx. Chi-Square & 657.638 \\
\hline \multicolumn{3}{|c|}{ Rotated Component Matrix } \\
\hline & Df & 55 & \\
\hline \multicolumn{3}{|c|}{ Component } \\
\hline \multicolumn{3}{|c|}{ Factor-1 } & Factor-2 \\
\hline Worst Pain & 0.053 & 0.798 \\
\hline Least Pain & 0.308 & 0.767 \\
\hline Average Pain & 0.189 & 0.861 \\
\hline Pain now & 0.376 & 0.627 \\
\hline Activity & 0.419 & 0.585 \\
\hline Mood & 0.743 & 0.050 \\
\hline Walking & 0.622 & 0.269 \\
\hline Work & 0.806 & 0.240 \\
\hline Relationship & 0.641 & 0.301 \\
\hline Sleep & 0.707 & 0.185 \\
\hline Enjoyment & 0.612 & 0.247 \\
\hline Extraction Method: Principal Component Analysis. \\
Rotation Method: Varimax with Kaiser Normalization. \\
Rotation converged in 3 iterations. \\
\hline
\end{tabular}

Table 8: Factor analysis for pain intensity and pain interference in both (TN and TMD) groups.

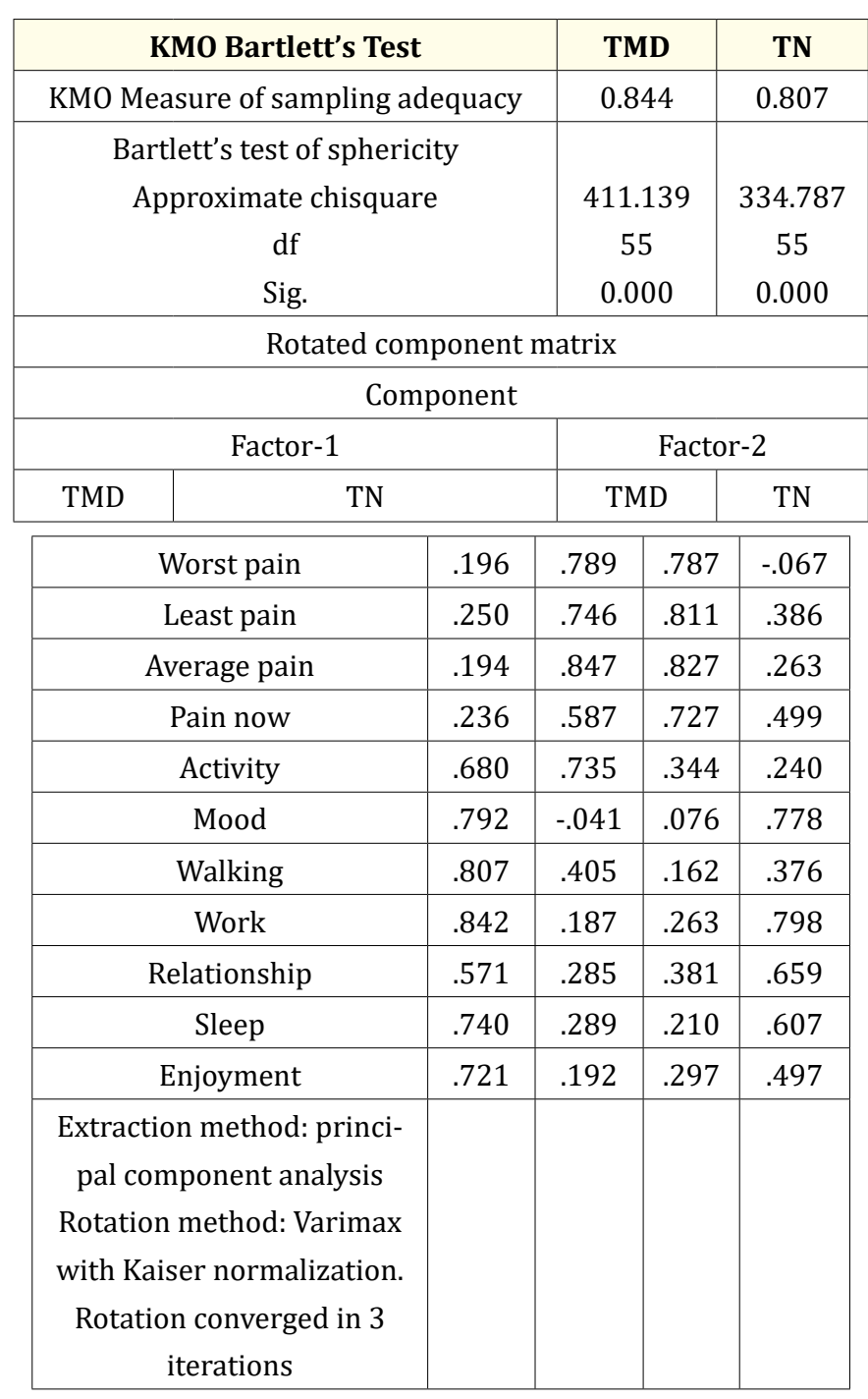

Table 9: Factor analysis for pain intensity and pain interference in individual group (TN and TMD).

\section{ROC curve analysis}

The validity indicators sensitivity, specificity, positive predictive value (PPV) and negative predictive values (NPV) were calculated. An ROC (receiver operating curve) analysis was performed to determine the cutoff value of BPI scores providing the best values of sensitivity (Sn), specificity (Sp), for diagnosis of patients with TN and TMD. Also, for each cutoff score, apart from Sn and Sp; negative predictive value (NPV), positive predictive value (PPV) according to standard criterion or reference diagnosis, the AUC (area under curve) is calculated and its significance level was estimated. The $95 \%$ confidence intervals $(95 \% \mathrm{CI})$ of the estimators of the cutoff paint selected as optimum were calculated. The data in figure 7 shows ROC analysis to find a best cut off value for activity score to categorize between TN and TMD. The data in table 10 shows Sn, Sp, 
NPV, PPV and overall accuracy values for this cut off score. To find a best cut off value for activity score to categorize between $\mathrm{TN}$ and TMD ROC curve analysis was done. A random classifier has an area under curve (AUC) value which equals to 0.5 ; the higher the value of AUC, the better distinguishing the capabilities of the classifier. In our study, the area under the AUC was 0.624 i.e., if the activity score is less than or equal to six, then it is categorized as TMD and if it is more than six it is categorized as TN (Figure 7). This cut off value has the Sn of $45.8 \%$ and Sp of $76.4 \%$, the NPV to be $58.5 \%$ and a PPV of $66.0 \%$.The overall accuracy to be $61.1 \%$ (Table 10 ). The data in figure 8 shows ROC analysis to find a best cut off value for sleep score to categorize between TN and TMD. The data in table 11 shows Sn, Sp, NPV, PPV and overall accuracy values for this cut off score. For sleep, the ROC curve analysis, revealed the AUC as 0.651 and showed the cut off value to classify as TMD to be $>4$. If it is less than or equal to 4 it can be categorized as TN (Figure 8). This cut off value has the Sn of $68.1 \%$ and Sp of $58.3 \%$ the PPV is $62 \%$ and NPV is $64.6 \%$. The overall accuracy is $63.2 \%$ (Table 11 ).

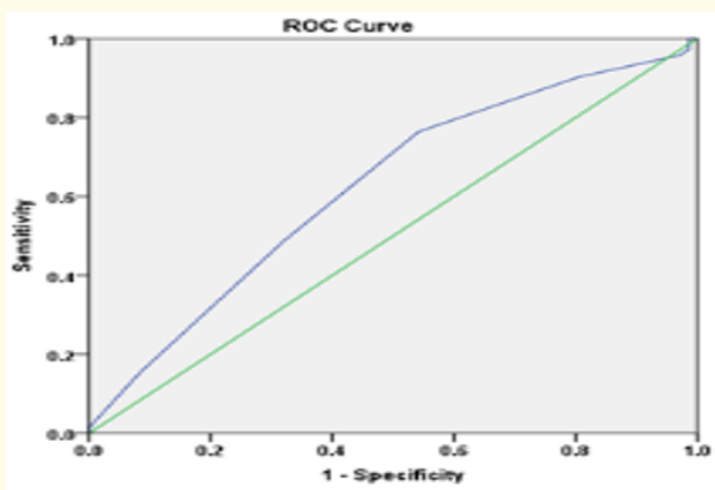

Figure 7: ROC Curve analysis to find a best cut off value for activity score to categorize between Tn and TMD.

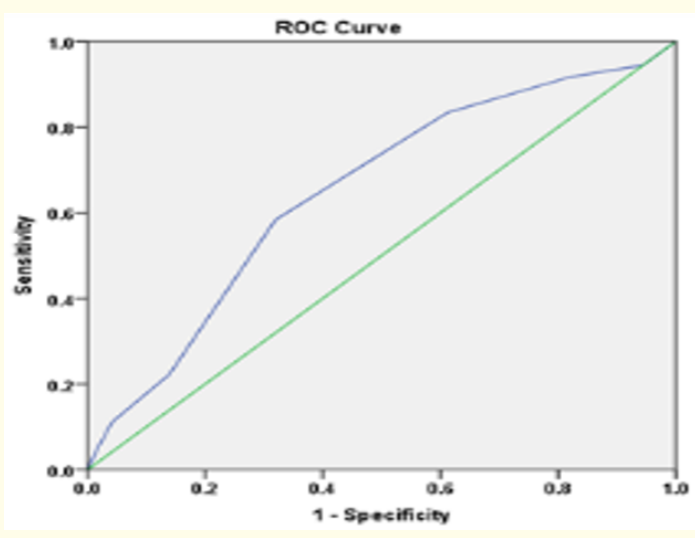

Figure 8: ROC curve analysis to find a best cut off value for sleep score to categorize between TN and TMD.

\begin{tabular}{|c|c|c|c|c|}
\hline \multicolumn{2}{|c|}{ TMD } & \multicolumn{2}{c|}{ Pain Group } & \multirow{2}{*}{ Total } \\
\cline { 3 - 4 } \multicolumn{2}{|c|}{} & TN & \\
\hline \multirow{2}{*}{ Activity score } & $\leq 6(\mathrm{TMD})$ & 33 & 17 & 50 \\
\cline { 2 - 4 } & $>6(\mathrm{TN})$ & 39 & 55 & 94 \\
\hline \multicolumn{2}{|c|}{ Total } & 72 & 72 & 144 \\
\hline \multicolumn{2}{|c|}{ Parameter } & \multicolumn{2}{|c|}{ Estimate } & $\mathbf{9 5 \%}$ CIs \\
\hline \multicolumn{2}{|c|}{ Sensitivity } & $45.83 \%$ & $(34.83,57.26)$ \\
\hline \multicolumn{2}{|c|}{ Specificity } & $76.39 \%$ & $(65.40,84.70)$ \\
\hline \multicolumn{2}{|c|}{ Positive Predictive Value } & $66.00 \%$ & $(52.15,77.56)$ \\
\hline Negative Predictive Value & $58.51 \%$ & $(48.41,67.95)$ \\
\hline \multicolumn{2}{|c|}{ Diagnostic Accuracy } & $61.11 \%$ & $(52.96,68.69)$ \\
\hline
\end{tabular}

Table 10: Sensitivity and specificity analysis for activity score.

\begin{tabular}{|c|c|c|c|c|}
\hline \multicolumn{2}{|c|}{ TMD } & \multicolumn{2}{c|}{ Pain Group } & \multirow{2}{*}{ Total } \\
\cline { 2 - 5 } & TN & & \\
\hline \multirow{2}{*}{ Sleep score } & $>4$ (TMD) & 49 & 30 & 79 \\
\cline { 2 - 4 } & $\leq 4$ (TN) & 23 & 42 & 65 \\
\hline \multicolumn{2}{|c|}{ Total } & 72 & 72 & 144 \\
\hline \multicolumn{2}{|c|}{ Parameter } & Estimate & $\mathbf{9 5 \%}$ CIs \\
\hline \multicolumn{2}{|c|}{ Sensitivity } & $68.06 \%$ & $(56.61,77.67)$ \\
\hline \multicolumn{2}{|c|}{ Specificity } & $58.33 \%$ & $(46.81,69.01)$ \\
\hline Positive Predictive Value & $62.03 \%$ & $(51.00,71.93)$ \\
\hline Negative Predictive Value & $64.62 \%$ & $(52.47,75.12)$ \\
\hline \multicolumn{2}{|c|}{ Diagnostic Accuracy } & $63.19 \%$ & $(55.07,70.63)$ \\
\hline
\end{tabular}

Table 11: Sensitivity and specificity analysis sleep score.

\section{Discussion}

The Task force on taxonomy of the International Association for the Study of Pain (IASP) defines pain as: "an unpleasant sensory and emotional experience associated with actual or potential tissue damage or described in terms of such damage" [9]. Literature reveals that pain assessment plays a significant role in studies related to clinical management, in conducting clinical trials which might help identify effective pain and epidemiology and health related policies that have a great impact on the patient's quality of life (QoL) [10]. TN is defined by the IASP as "a sudden usually unilateral, severe, brief, stabbing, recurrent pain in the distribution of one or more branches of the fifth cranial nerve" and is prevalent in $2-3 \%$ of the population $[7,11]$. According to American academy of orofacial pain, TMD is defined as "a collective term embracing a number of clinical problems that involve the masticatory muscles, the temoromandibular joint and associated structures or both". It is prevalent in among 6-12\% of the population $[8,12]$. 
Most of the TN patients in our study were in the age group of 4150 years $(54.2 \%)$ and above 60 years $(40.3 \%)$. Several studies have revealed the peak incidence of $\mathrm{TN}$ in 50-60 years and an increase with age [13]. In our study in the age group of 21-40 years (63.9\%) TMD was mostly seen. These findings were similar to the study done by Mandfredini D et al [14]. Among the total 144 study subjects, $49.3 \%$ i.e., 71 were males and $50.7 \%$ i.e. 73 were females in the study. In the TMD group, there were 43 females and 29 males. These findings coincided with the studies done by Wadhwa $S$ et al which say that TMD is more prevalent in women [15]. There were 42 males and 30 females in the TN group in our study. Though TN is more prevalent in women, the findings of our study were similar to the study done by Umar et al [16].

As pain includes sensory and emotional components it can be expressed in different ways. Verbal communication of pain complaint, facial and body expression, social dysfunction and physical dysfunction may all be displayed in one individual, whereas another individual may complain less but use facial expression, and a third person may exhibit social or physical dysfunction. Hence, pain is considered to be a multidimensional entity in which the impact of pain on a patient's life and degree of disability are important to consider when planning treatment. Verbal pain descriptors have an importance in recording the patient's perception of pain. Several studies done earlier on McGill pain questionnaire (MPQ) have shown that effective description of pain helps in understanding its underlying mechanism. Dubuisson and Melzack in 1976 found that MPQ can be used to discriminate different kinds of pain [17]. In their study the discriminant analysis was $77 \%$ correct in making a prediction of the patients' clinical pain problem on the basis of verbal descriptors alone. Several other studies have confirmed the discriminative capacity of the MPQ [18,19] while a few have found that severe pain may obscure the MPQ's discriminative ability $[20,21]$. Ronald Melzack et al did a study using MPQ to know the discriminative capacity of pain in patients of trigeminal neuralgia and atypical facial pain, where most of the patients in the trigeminal neuralgia group chose flashing, terrifying, blinding, and torturing words to describe their pain [22]. In a similar study done by Mongini $\mathrm{F}$ et al in using MPQ in patients with TMJ disorders and myogenous pain, the TMJ group chose tiring, troublesome, nagging, sore, tender, and aching words to describe their pain whereas in the myogenous pain group the descriptors most frequently chosen were exhausting, punishing and pulling [23]. Pedroni et al used MPQ in group of TMD patients with cervical spine disorders where most of the patients chose the words "pressing", discomfortable and "annoying" [24].

Most of the trigeminal neuralgia patients in our study chose "sharp, stabbing, shooting, burning, numb and unbearable" to describe their pain and they were highly statistically significant $(\mathrm{p}<$ 0.001). These findings were similar to the typical description of pain in TN [11]. Among TMD patients statistically significant words were "aching, nagging" ( $\mathrm{p}<0.001)$ and these findings were mostly similar to the study done by Mongini F et al [23]. A Chi-square test done to compare the proportions between these two pain groups revealed statistical significance of $(p<0.001)$.

Several studies have shown that an increase in automatic hyperactivity has often been linked to anxiety and depression caused due to chronic pain. This leads to impairment and loss of function $[25,26]$. Mood disorders sleep disturbances, opioid dependence, alteration in perception and behavioral changes were linked to chronic pain states in the study done by Hansen et al [27]. A study by WHO showed that individuals who live with persistent pain are four times more likely than those without pain to suffer from depression or anxiety and more than twice as likely to have difficulty in working [28]. In our study, the mean values of pain interference scores in study subjects revealed statistical significance in both activity ( $p=0.035)$ and sleep ( $p=0.693)$. The independent sample $\mathrm{t}$ - test result shows that the two mean values for activity in TN and TMD groups were statistically significant $(p=0.035)$. Also, the two mean values are statistically significant $(p=0.003)$ for sleep in TN and TMD groups.

Quality of life (QoL) is defined as individual's ability to perform a range of roles in society and to reach an acceptable level of satisfaction from functioning in those roles [29,30]. Hunfeld and researchers found that QoL decreased as intensity and frequency of pain increased [31]. One of the most impressive findings were seen in the results of a study where the health related quality of life (HrQoL) was assessed in chronic non cancer and advanced cancer pain patients where the patients with chronic non cancer pain reported even worse QoL than dying cancer patient, a dramatic illustration of the major impact of chronic pain conditions on the global situation of persons with long lasting pain [32,33]. In our study, pain intensity interfered maximum with activity and mood. In the study done by Erdemoglu $\mathrm{AK}$ et al, the pain intensity interfered with activity, sleep and mood [34]. 
In our study, correlations between pain intensity and pain interference scores in both the groups showed a positive value for Pearson's coefficient $(r)=0.614$ and a high statistical significance $(\mathrm{p}<0.001)$. Individually the correlation coefficients between pain intensity and pain interference showed ( $\mathrm{r}$ ) $=0.558$ (TMD group) and $r=0.676(\mathrm{TN})$, both revealing high statistical significance $(\mathrm{p}<$ 0.001). However, correlation coefficients alone do not rule out the reliability of the test instrument. In our study, we did not do the test- retest stability.

Identification of factor loading was done by performing factor analysis for pain intensity and pain interference scores. The results of the factor analysis identified two factors, one factor involved with all pain intensity variables and activity of pain interference and the other factor involved with all pain interference variables except activity. Factor analysis done for pain intensity and interference scores in TMD group showed KMO Bartlett's Measure of Sampling Adequacy to be 0.857 with a $\mathrm{p}$ value of $<0.001$ where as in TN group showed 0.807 with a $p$ value of $<0.0001$. When factor analysis for pain intensity and pain interference was done in each group, KMO Measure of Sampling Adequacy is 0.844 with a p-value $<0.001$ in TMD group. Factor analysis result identified two factors, one factor with all pain intensity variables and the other factor involving with all pain interference variables. Kaiser-Meyer-Olkin Measure of Sampling Adequacy is 0.807 with a p-value $<0.001$ in TN group. The factor analysis results identified two factors, one factor with all pain intensity variables and the other factor evolves with all pain interference variables except walking. In the study done by Erdemoglu et al factor analysis done using the method of principal axis factoring and direct oblimin rotation revealed that BPI is composed of the severity and pain interference on activity, mood and sleep interactions (three factors) [34]. The standard BPI has generally exhibited a two- factor structure such as pain intensity and impact of or pain interference. However, there are also others studies which have stated that BPI may also exhibit three factor structures $[35,36]$.

The results of ROC analysis to find a best cut off value for activity score to categorize between TN and TMD in our study revealed, the area under curve (AUC) to be 0.624 i.e., if the activity score is less than or equal to six, then it is categorized as TMD and if it is more than six it is categorized as TN. This cut off value had a Sn of $45.8 \%$ and Sp of $76.4 \%$, NPV of $58.5 \%$ and the PPV to be $66.0 \%$. The over- all accuracy is $61.1 \%$. For sleep, the ROC curve analysis, showed the cut off value to classify as TMD to be $>4$. If it is less than or equal to 4 it can be categorized as TN. This cut off value had the Sn of $68.1 \%$ and Sp of $58.3 \%$, a PPV of $62 \%$ and the NPV to be $64.6 \%$. The overall accuracy is $63.2 \%$. In the study done by Erdemoglu et al the ROC curve plotted for the total score showed area under curve (AUC) as 0.69 and the Sn, Sp, PPV and NPV values for criterion total BPI score were $79.37 \%, 46.9 \%, 65.8 \%$, and $63.9 \%$, respectively [34].

When asked to talk about their pain, patients are often left entirely on their own to come up with a format for communicating the characteristics and intensity of their pain often leading to an unstructured communication and maximizing the chances of personality, cultural, linguistic and situational variability and related communicational bias. However, such an interchange is not a measurement situation in any sense. By using a standardized set of questions that are to be asked and by introducing measurement scales designed to measure subjective response, this variability in response can be dramatically mitigated. MPQ was validated to evaluate the sensory, affective and evaluative aspects of orofacial pain [37]. However, the MPQ mainly measures the qualities of pain and it does not assess how pain interferes with patient's functioning. Most unidimensional (assessing only pain intensity or interference) pain rating scales oversimplify the assessment of some types of pain [38]. The BPI is easily understood by patients and takes short time to complete, could be self-administered for literate patients or be completed by interview for illiterate patients. The form of administration has little effect on outcome. Several studies have shown that BPI can be easily translated for non- English speaking patients. BPI can be used in studies of the epidemiology of pain, in the clinic, in effectiveness of treatments and their outcomes. The validity of BPI has been well documented by many studies previously [35,36,39-41].

The present study is unique in doing the validation in trigeminal Neuralgia and temoporomandibular joint disorder patients. Our study demonstrates that BPI is a valid tool for evaluating the pain's intensity and its interference in trigeminal neuralgia and temporomandibular joint disorder patients. The limitations of this study include the non-examination of treatment outcome measures and test-re-test stability as this study is a validation of BPI and descriptors for trigeminal neuralgia and temporomandibular joint disorders. Though AUC, sensitivity and specificity of BPI are not excellent, it has higher value than a random classifier. 
Validity of Brief Pain Inventory Questionnaire in Describing Trigeminal Neuralgia and Temporomandibular Joint Disorder Patients

\section{Conclusion}

In conclusion, as BPI assesses the severity of pain and its impact on daily functioning and other aspects of pain its use as a diagnostic tool alone can be improved by developing new questions and precision tests further in clinical studies.

\section{Acknowledgements}

The study was done in the department of oral medicine and radiology at Saveetha Dental College and Hospitals, Chennai. The design of the study concept and data analysis was done by Dr. Arvind Muthukrishnan. The manuscript writing and the study was done by Dr. K. Caroline Sunitha.

\section{Conflict of Interest}

No conflict of interest.

\section{Bibliography}

1. Hapak L., et al. "Differentiation between musculoligamentous, dentoalveolar, and neurologically based craniofacial pain with a diagnostic questionnaire". Journal of Orofacial Pain 8.4 (1994): 357-368.

2. Mark A Lumley., et al. "Pain and Emotion: A Biopsychosocial Review of Recent Research". Journal of Clinical Psychology 67.9 (2011): 942-968.

3. Talbot K., et al. "The sensory and affective components of pain: are they differentially modifiable dimensions or inseparable aspects of a unitary experience? A systematic review". British Journal of Anesthesia 123.2 (2019): e263-e272.

4. Cleeland CS. "Pain control: public and physicians' attitudes". In hill CS JR, fields WS Eds, Advances in Pain Research and Therapy. Newyork: raven press 11 (1989): 81-89.

5. Marzinski LR. "The tragedy of dementia: clinically assessing pain in the confused non-verbal elderly". Journal of Gerontological Nursing 17.6 (1991): 25-28.

6. Cleeland CS and Ryan KM. "Pain assessment: global use of the brief pain inventory". Annals of the Academy of Medicine Singapore 23.2 (1994): 129-138.

7. Toda K. "Trigeminal neuralgia - symptoms, diagnosis, classification and related disorders". Oral Science International 4.1 (2007): 1-9.

8. Dworkin SF and Leresche L. "Research diagnostic criteria for Temporomandibular disorders: review, criteria, examinations and specifications, critique". Journal of Craniomandibular Disorders : Facial and Oral Pain 6.4 (1992): 301-355.
9. Merskey H and Bogduk N. "Part III: Pain Terms, A Current List with Definitions and Notes on Usage". Classification of chronic pain, Second Edition, IASP Task Force on Taxonomy, edited IASP Press, Seattle, (C) (1994): 209-214.

10. Stubhaug A., et al. "Assessment of Pain". British Journal of Anaesthesia 101.1 (2008): 17-24.

11. Rahul Srivastava., et al. "Diagnostic criteria and management of trigeminal neuralgia: A review". Asian Pacific Journal of Health Sciences 2.1 (2015): 108-118.

12. Lipton JA., et al. "Estimated prevalence and distribution of reported orofacial pain in the United States". Journal of American Dental Association 124.10 (1993): 115-121.

13. Katusic S., et al. "Incidence and clinical features of trigeminal neuralgia, Rochester, Minnesota, 1945-1984". Annals of Neurology 27.1 (1990): 89-95.

14. Manfredini D., et al. "Research diagnostic criteria for temporomandibular disorders: a systematic review of axis I epidemiologic findings". Oral Surgery Oral Medicine Oral Pathology Oral Radiology and Endodontics 112 (2011): 453-462.

15. Wadhwa S and Kapila S. "TMJ Disorders: future innovations in diagnostics and therapeutics". Journal Dental Education 72.8 (2008): 930-947.

16. Umar., et al. "Trigeminal neuralgia: a study on 242 patients". Pakistan Oral and Dental Journal 25.2 (2005): 163-166.

17. Dubuisson D and Melzack R. "Classification of clinical pain descriptions by multiple group discriminant analysis". Experimental Neurology 51.2 (1976): 480-487.

18. Chen AC and Treede RD. "The Mc Gill pain questionnaire in the assessment of phasic and tonic experimental pain: behavioural evaluation of the 'pain inhibiting pain' effect". Pain 22.1 (1985): 67-79.

19. Grushka M and Sessle BJ. "Applicability of the McGill Pain Questionnaire to the differentiation of 'toothache' pain". Pain 19.1 (1984): 49-57.

20. Kremer EF., et al. "The language of pain: Affective descriptors of pain are a better predictor of psychological disturbance than pattern of sensory and affective descriptors". Pain 16.2 (1983): 185-192.

21. Wagstaff S., et al. "Verbal pain descriptors used by patients with arthritis". Annals of Rheumatic Disease 44.4 (1985): 262265. 
22. Melzack R. "The short-form McGill pain questionnaire". Pain 30.2 (1987): 191-197.

23. Mongini F and Italiano M. "TMJ disorders and myogenic facial pain: a discriminative analysis using the McGill Pain Questionnaire”. Pain 91.3 (2001): 323-330.

24. Pedroni C R., et al. "Pain characteristics of temporomandibular disorder - a pilot study in patients with cervical spine dysfunction". Journal of Applied Oral Sciences 14.5 (2006): 388-392.

25. Wagner AM., et al. "Pain prevalence and pain treatments for residents in Oregon nursing homes". Geriatric Nursing 18.6 (1997): 268-272.

26. Fishbain DA. "Approaches to treatment decisions for psychiatric comorbidity in the management of the chronic pain patient". The Medical Clinics of North America 83.3 (1999) :737760.

27. Hansen GR and Streltzer J. "The psychology of pain". Emergency Medicine Clinics of North America 23.2 (2005): 339-348.

28. Gureje 0., et al. "Persistent pain and well-being: A World Health Organization study in primary care". JAMA 280.2 (1998): 147151.

29. Rummans TA., et al. "Quality of life and pain in patients with recurrent breast and gynaecologic cancer". Psychosomatics 39.5 (1998): 437-445.

30. Anderson RB., et al. "Physical Symptoms Distress Index: a sensitive tool to evaluate the impact of pharmacological agents on quality of life". Archives of Internal Medicine 159.7 (1999): 693-700.

31. Hunfeld JA., et al. "Chronic pain and its impact on quality of life in adolescents and their families". Journal of Pediatric Psycholoy 26.3 (2001): 145-153.

32. Fredheim OMS., et al. "Validation and comparison of the health related quality of life instruments EORTC-QLQ-C30 and SF-36 in assessment of patients with chronic non-malignant pain". Journal of Pain and Symptom Management 34.6 (2007): 65765.

33. Fredheim OMS., et al. "Chronic non-malignant pain patients report as poor health-related quality of life as palliative cancer patients". Acta Anaesthesiologica Scandinavica 52.1 (2008): 143-148.
34. Erdemoglu AK and Koc R. "Brief Pain Inventory score identifying and discriminating neuropathic and nociceptive pain". Acta Neurologica Scandivica 128.5 (2013): 351-358.

35. Klepstad P., et al. "The Norwegian brief pain inventory questionnaire: translation and validation in cancer pain patients". Journal of Pain and Symptom Management 24.5 (2002): 517525.

36. Radbruch L., et al. "Validation of the German version of the Brief Pain Inventory". Journal of Pain and Symptom Management 18.3 (1999): 180-187.

37. Van Buren J and Kleinknecht R A. "An evaluation of the McGill pain questionnaire for use in dental pain assessment". Pain 6.1 (1979): 23-33.

38. Dworkin RH., et al. "Interpreting the clinical importance of treatment outcomes in chronic pain clinical trials: IMMPACT recommendations". Journal of Pain: official journal of the American Pain Society 9.2 (2008): 105-121.

39. Ger LP., et al. "Validation of the Brief Pain Inventory in a Taiwanese population". Journal of Pain Symptom Management 18.5 (1999): 316-122.

40. Aisyaturridha A., et al. "Validation of the Malay Brief Pain Inventory questionnaire to measure cancer pain". Journal of Pain Symptom Management 31.1 (2006): 13-21.

41. Kalyadina SA., et al. "Russian Brief Pain Inventory: validation and application in cancer pain". Journal of Pain and Symptom Management 35.1 (2008): 95-102.

\section{Assets from publication with us}

- Prompt Acknowledgement after receiving the article

- Thorough Double blinded peer review

- Rapid Publication

- Issue of Publication Certificate

- High visibility of your Published work Website: www.actascientific.com/ Submit Article: www.actascientific.com/submission.php Email us: editor@actascientific.com

Contact us: +919182824667 